\title{
A Centrifuge Calibrator Based on Personal Computer Equipped with Data Processor
}

\author{
Habliya Asadina\#, Torib Hamzah, Dyah Titisari, Bedjo Utomo \\ Department of Electromedical Engineering Poltekkes Kemenkes, Surabaya \\ Jl. Pucang Jajar Timur No. 10, Surabaya, 60245, Indonesia \\ "habliyaasadinaa@gmail.com, trbhamzah@yahoo.co.id, ti2_sari@yahoo.com, bedjoutomo123@gmail.com
}

\begin{abstract}
Calibration is an activity to determine the conventional truth of the value of the appointment of a measuring instrument by comparing traceable standards to national and international standards for measurement or international units and certified reference materials. The purpose of this study is to develop a system of efficient and practical centrifuge calibrators by sending the calibration results directly via Bluetooth to a PC. The main series of centrifuge calibrators are Arduino modules, laser sensors, and Bluetooth. The high low signal is obtained from the reflection of the laser beam aimed at the reflector point on the centrifuge plate, processed in the Arduino module and displayed on the LCD, the calibration results can be directly seen in the Delphi program. The design of this module is also equipped with a Bluetooth transmitter to send data to a PC. This module can be used in medical equipment calibration laboratories. Based on the results of testing and data collection on the 8 Tube centrifuge with a Lutron Tachometer ratio, the error value was $0.0136 \%$. After planning, experimenting, making modules, testing modules, and collecting data, it can be concluded that the tool "centrifuge calibrator equipped with PC-based data processors" can be used and according to planning because the fault tolerance does not exceed $10 \%$.
\end{abstract}

Keywords-Tachometer; RPM; 5MW laser sensor

\section{INTRODUCTION}

Calibration is an activity to determine the conventional truth of the value of the appointment of measuring and measuring materials by comparing traceable standards to national and international standards for measurement or international units and certified reference materials [1]. One medical device that needs to be calibrated is a centrifuge, while the tool for calibrating the centrifuge is a tachometer. The Tachometer is a testing device designed to measure the rotational speed of an object, such as a measuring device in a car that measures the rotation per minute (RPM) of an engine crankshaft. The word tachometer comes from the Greek word taco's which means speed and metron which means to measure. The working principle of a tachometer device is to measure the rotation of the engine shaft of the device resembling an electric generator which varies according to the speed of engine rotation. The electricity generated is then converted in RPM [2].

At present, the average calibration laboratory uses a noncontact tachometer that still uses manual data recording, according to the author's observation that the recording time of manual calibration results is not efficient, plus several error factors such as human error and measurement angle. The results of the centrifuge speed measurement must be done, this is related to the accuracy of the results of reading the data.

Previous research by Andrik Budi K (2011) made a NonContact Tachometer Based on Microcontroller Via Serial RS232 to a Personal Computer using a DC laser. The DC laser here is used as a light transmitter and phototransistor as a light receiver.
Then Tera Hanifah (2016) made an Atmega 8 Microcontroller Based Tachometer Equipped with Hold Mode, which is used to stabilize the measurement process. In the same year, Mamik (2016) also made an Arduino-based non-contact Tachometer, but it was not equipped with a hold mode. In the following year, Novella (2017) made research on Tensimeter Calibrator Equipped with PC-Based Thermo hygrometer. The latest research by Septian Aan Cahyani made the centrifuge calibrator equipped with data processors (2018), but according to the author, the authors still have weaknesses because the facts in the field during the calibration process take a long time because they have to write data first to the worksheet [3], then enter data into the PC manually to find out the results. This process allows for errors caused by human error when entering data manually.

By looking at the chronology above, the author tries to make a centrifuge Calibrator with PC-based data processors. The tool that will be made is equipped with sending the measurement data automatically to the $\mathrm{PC}$, then the process and the calibration results can be obtained directly.

\section{MATERIALS AND METHODS}

\section{A. Experimental Setup}

This study was randomly sampled and the data collection is repeated for 5 times. this research uses micro hematocrit and 12000 RPM centrifuge.

\section{1) Materials and Tools}

This study uses double tape as a reflector on a centrifuge plate of $8 \mathrm{~mm}-12 \mathrm{~mm}$. Arduino Uno microcontroller is used as a 
digital data processor and communication to the computer unit using Bluetooth module HC-05.

\section{2) Experiment}

In this study, the centrifuge calibrator was compared with the Lutron tachometer which is calibrated by the company, in all ranges (1000, 2000, 3000, 4000, 12000 RPM). Each setting, the calibrator's output is calculated to validate the results of this study.

\section{B. The Diagram Block}

The transmitter emits a laser beam which is then fired at the object. The object is given a white line as a reflective field that will be captured by the receiver. The receiver outputs a digital signal that will be forwarded and converted in the form of an RPM by the microcontroller. The RPM value will be displayed on the $2 \times 16$ LCD display. Press start to start the measurement and if the measurement is stable press the stop button. The measurement results will be displayed on the display, and press the save button, it will immediately be sent to the PC. The delete button is only used to delete all data from the measurement results.

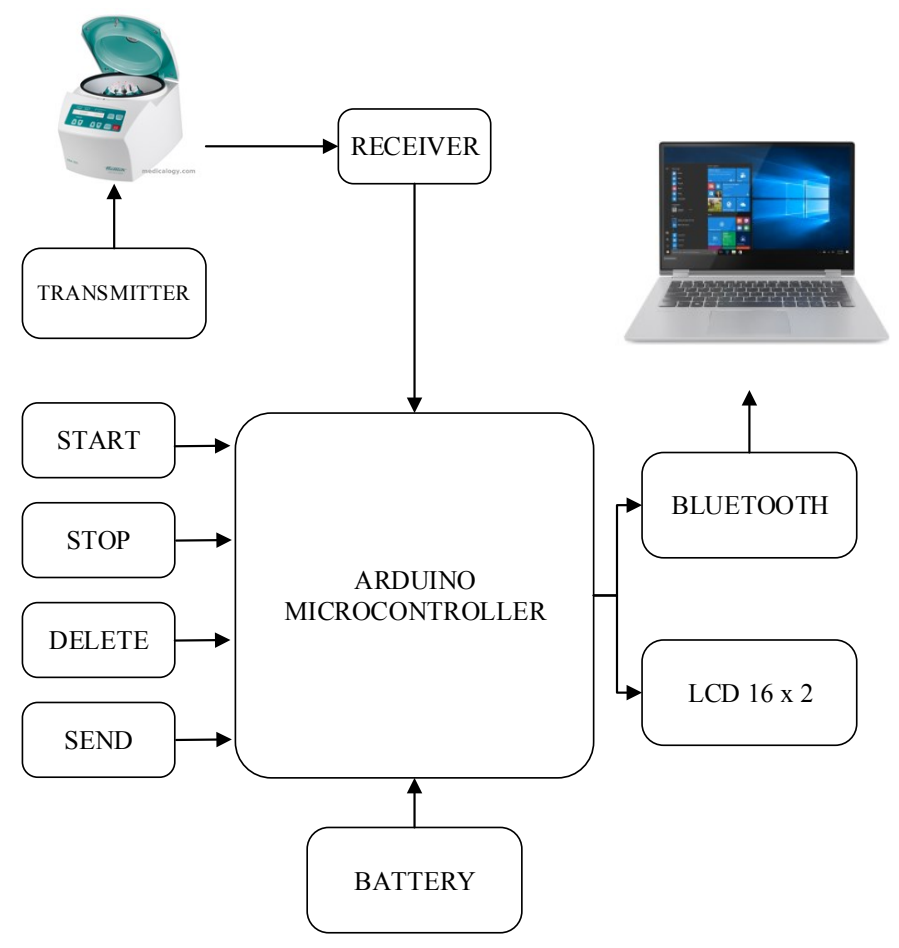

Fig. 1. The diagram block of the RPM calibrator

When the ON / OFF button, the whole circuit will get a supply voltage from the battery. When the centrifuge round is stable enough, then press the start button to start the measurement and after the results showed are quite stable press the stop button the results will be displayed on the LCD. If you want to repeat the measurement, press the delete key, then the LCD will start the initialization again. After the measurement results are correct, press the send button to send the results to the
Delphi program. After all data has been sent, data processing takes place. Each speed parameter will be repeated six times.

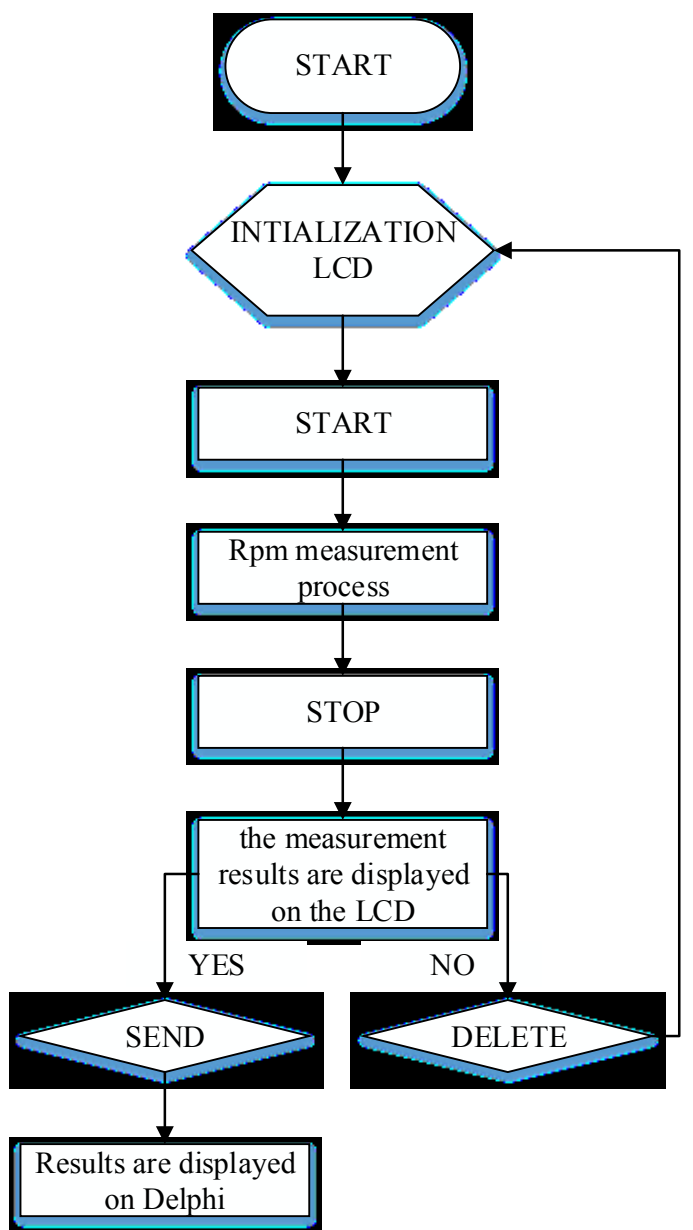

Fig. 2. The Flowchart of the Arduino Program

\section{The Flowchart}

The Arduino program was built based on the flowchart as shown in Fig. 2. After the initialization of the Arduino, sensor starts calculating the centrifuge speed and the results are processed by Arduino, if the results are correct, it will be displayed on the LCD. The measurement results on the LCD will be sent via Bluetooth to the Delphi program.

\section{The Laser Sensor}

The important part of this development is the laser sensor which describes in Fig. 3. The sensor is used to process the centrifuge RPM. Hence it will ready for digital processing using Arduino. 

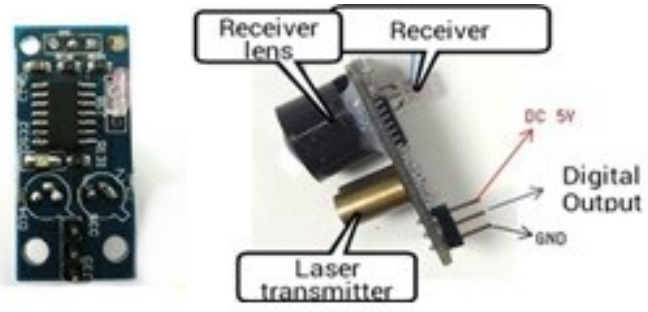

Fig. 3. The calibrator centrifuge design

This sensor consists of 2 parts, namely the transmitter and receiver. In the transmitter section, there are 2 oscillation tubes that can produce shock waves with a frequency of $180 \mathrm{kHz}$. After being amplified by the transistor, the shock wave is sent to activate the laser tube. At the receiver, there is a receiving tube that matches and fits the oscillating tube so that it can receive light reflection.

1) Bluetooth Module

The Bluetooth (BT) module used in this was HC-05. This Bluetooth module was used to transmit the calculation results of centrifuge speed to the computer unit. For the communication between the Arduino board and the Bluetooth module, it needs two pins which are Tx (to transmit the ECG Data, and The Rx is to receive the information between the microcontroller and computer unit). The connection between the BT and Arduino module was shown in Fig. 7.

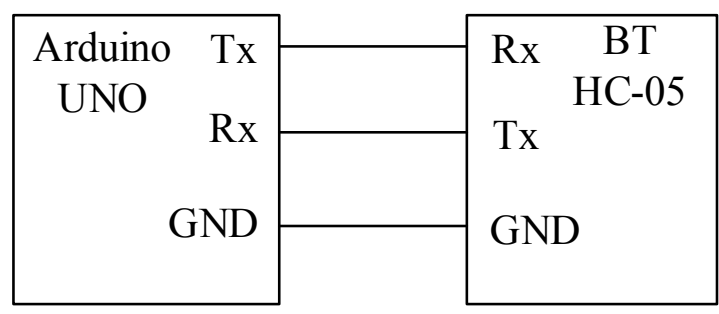

Fig. 4. Bluetooth Connection

\section{RESULTS}

In this study, the centrifuge calibrator was compared with the Lutron tachometer.

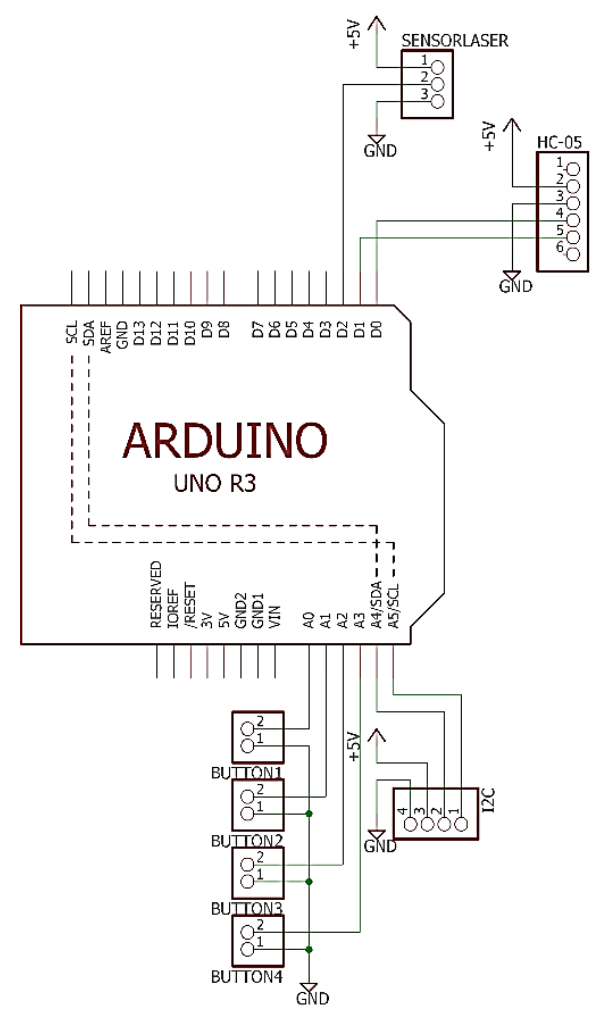

Fig. 5. The calibrator centrifuge design

\section{1) The calibrator centrifuge Design}

This circuit is a microcontroller circuit that serves to regulate the running of the system. Push-button 1 is connected to the Arduino UNO A0 pin, pushbutton 2 is connected to pin A1, push-button 3 is connected to pin A2, push-button 4 is connected to pin A3. 16x2 LCD is used to display RPM.

Push-button 1 is used to start the calculation of the motor centrifuge speed. When push button 1 is pressed (logic 1), the program will detect the input on pin 2 then the program will run the logic reading mechanism, so the program will run for calibration.

Push-button 2 is used to stop the RPM speed calculation. When push button 2 is pressed (logic 1), the program will execute the command to stop the command.

Push-button 3 is used to erase data when an error occurs when the push-button reset is pressed (logic 1), the program will detect the input on the $\mathrm{A} 3$ pin then the program will run the logic reading mechanism, so the clear data command will run. Push-button 4 is used for sending calibration results to a PC via Bluetooth. When push button 4 is pressed (logic 0 ), the data on rpm will be sent to the Delphi worksheet. 

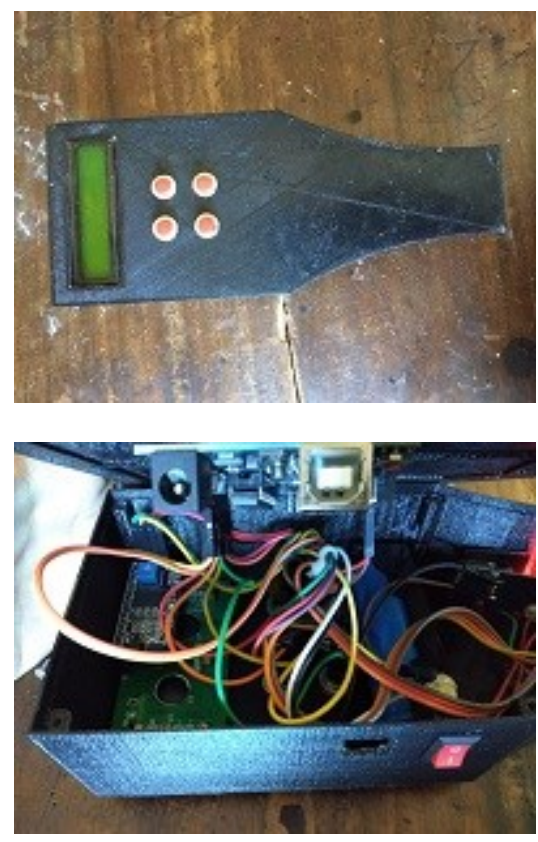

Fig. 6. The box design

2) The Listing Program for Arduino Calibrator Centrifuge In this paper, the software was divided into two sections which are for Arduino and Delphi programming. The listing program for Arduino as shown in the Listing Program 1. Which consisted of the program to send the data to the computer which can be chosen in the initial program.

Listing program 1. Program to Counter RPM centrifuge

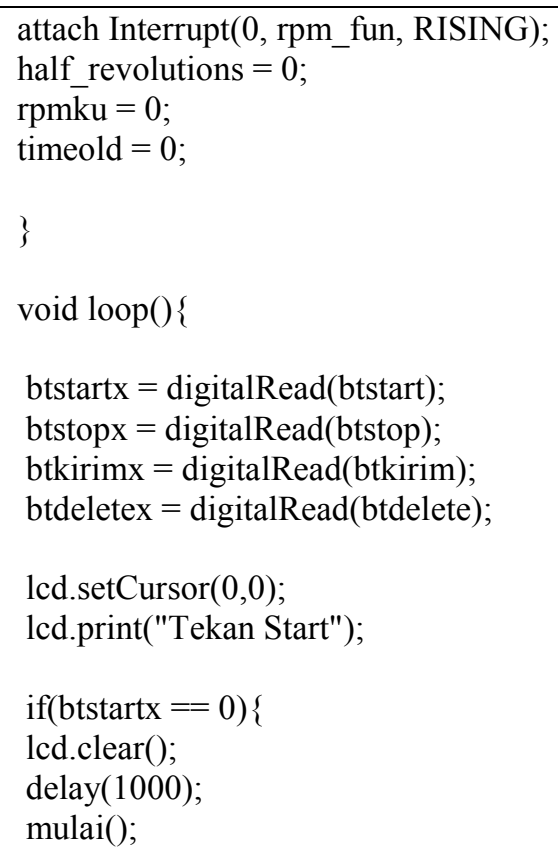






\section{3) The Listing Program for Delphi Calibrator centrifuge} In the Delphi programming, the program explains the acceptance of the results of calibration and inserted into the cell. Listing Program 3. Program to display the RPM number

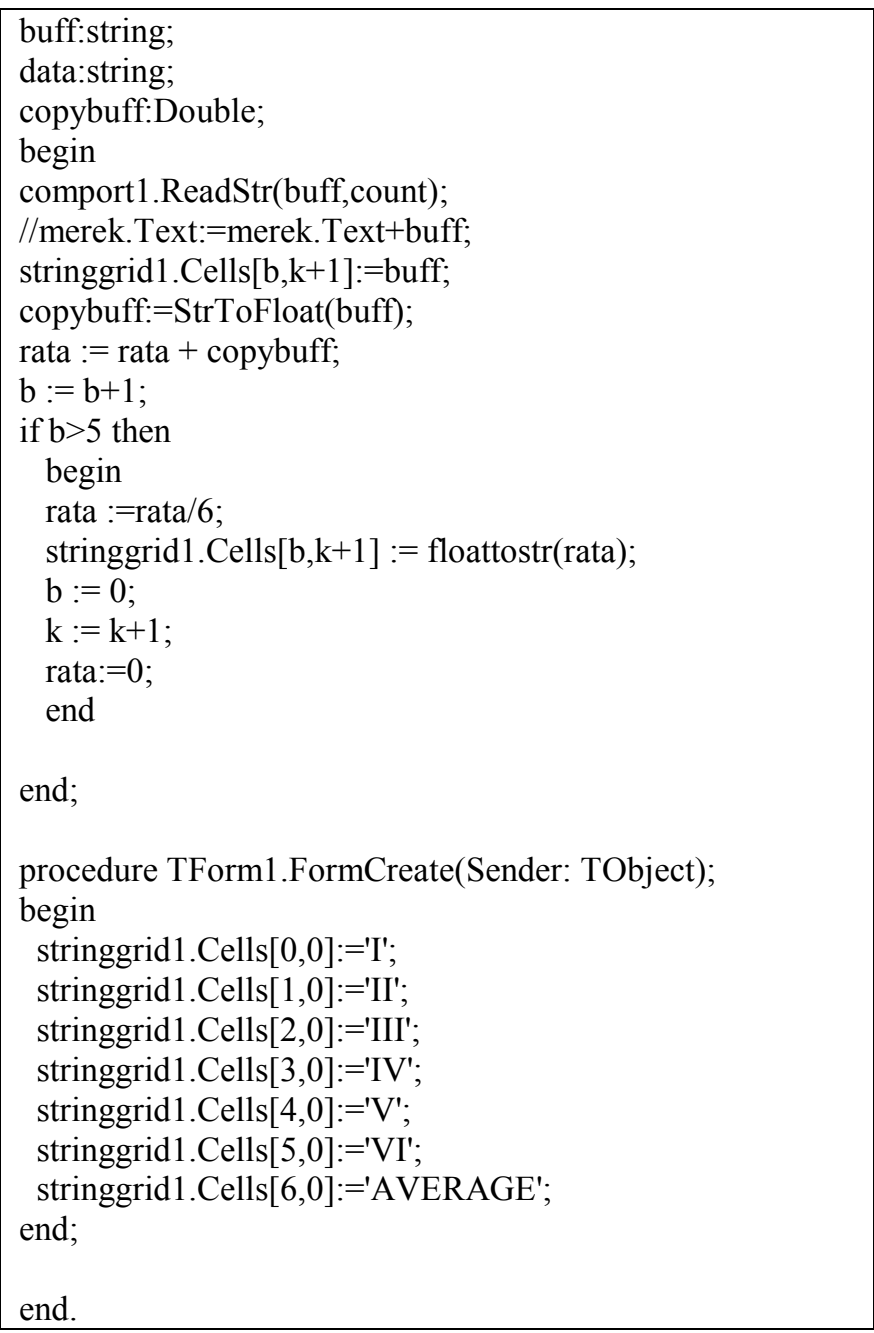

The Delphi programming received the RPM centrifuge data from BT and saved to the computer by using the ComDataPacket function. Furthermore, the RPM centrifuge will then displayed into the cells.

\section{4) The Error of RPM value}

The validation of the RPM value shown in the Delphi programming was compared with the Tachometer Lutron device. The error was showed in Table I.
TABLE I. THE ERROR OF MEASUREMENT FOR THE RPM PARAMETER BETWEEN THE DESIGN AND STANDARD DEVICE.

\begin{tabular}{cc}
\hline RPM & Error(\%) \\
\hline 1000 & 0,1991 \\
2000 & 1,3613 \\
3000 & 0,9761 \\
4000 & 0,8192 \\
12000 & 0,1191 \\
\hline
\end{tabular}

\section{DISCUSSION}

The Holter design has been examined and test completely in this study. Based on the measurement of the Holter output, the resulted ECG signal when using the input from ECG simulator showed the right pattern of ECG signal which consisted of $\mathrm{P}, \mathrm{Q}$, $\mathrm{R}, \mathrm{S}$, and $\mathrm{T}$ waveform with the amplitude of $1 \mathrm{mV}$, for various BPM $(30,60,120,180$ and 240), and sensitivity of $1 \mathrm{mV}$.

By comparing the output of the Holter between the input using ECG simulator and the human body, It was shown that there is a different pattern on PQRST waveform. Each ECG recording for each subject showed a different amplitude. This is reasonable because each subject has different characteristics of the heart. The Error of BPM between the design and Oximetry device (with the input from ECG simulator) showed the value of $0.0037 \pm 0.010$. The error of BPM (from the five subjects) is $0.00057 \pm 0.0008$. This error value indicated that the Holter is feasible to be used as a medical device. In order for the Holter able to work in 24 hours then this design needs a battery with high capacity.

The performance of this work was also compared to other works. Carrasco found that his Holter is able to operate in 16 hours without the intervention of the users [5]. Jin and Miao claimed that their Holter able to work stable more than 24 hours [4].

\section{CONCLUSION}

This After processing the program to receive RPM data from the laser sensor module, it is able to read the RPM in the centrifuge with an error between the comparison to the module that is equal to $1.3613 \%$. In general, it can be concluded that this tachometer module can be used as a measuring device for RPM (Rotation Per Minute) in Centrifuge with speeds up to 12000, due to error values which are still below the maximum limit of $10 \%$. High error factor results due to the comparison of the module average values with high comparison.study has demonstrated the development of the Holter to monitoring the ECG signal from a subject with real-time. This study was built based on an Arduino microcontroller and some analog circuit and a Bluetooth transmitter to connect to the Computer unit. This study has proofed that the accuracy is feasible to be used to monitor the ECG signal in real-time and the data recording can be read from the SD card memory. In the future, this study can be fabricated and used in the small clinic in the villages at a low cost. 


\section{REFERENCES}

[1] [KIM LIPI, "DEFINISI KALIBRASI -Info Kalibrasi," 2017. [Online]. Available: http://infokalibrasi.blogspot.com/2012/10/definisikalibrasi.html.

[2] Enny, "Jurnal Metana," Tachom. Laser, Pemakaian And Perawatannya, vol. 13 , no. 1, pp. 7-12, 2017.

[3] P. SMS, "metode kerja kalibrasi," 2014.

[4] Triarjo, S. Rianto, A. Muchsin, and E. Muljono, "Jurnal Pusat Teknologi Bahan Bakar Nuklir," Anal. Kerusakan Centrifuge ( Xd-301 ) Pada Proses Pemisahan Uranil Nitrat Seksi 300 Instal. Pcp, vol. 2, no. 16, pp. 13-20, 2016.

[5] World Health Organization, "WHO Laboratory-doc," vol. 2, p. 45, 2008.

[6] PERMENKES, "PENGUJIAN AND KALIBRASI ALAT KESEHATAN," 2015.

[7] ECRI, Health Devices IPM System, 456th-200103rd ed. 2001.

[8] Criteria for Medical Equipmen Inventory Inclusion. 2008.

[9] T. Darmana and W. Sya'ban, "JURNAL ENERGI \& KELISTRIKAN," Ranc. BANGUN ALAT UKUR KECEPATAN PUTARAN Mot. AND PENDETEKSI KESTABILAN PUTARAN PADA POROSNYA, vol. 7, no. 1, pp. 71-76, 2015.

[10] W. Amaldi, “Arduino penjelasan and macamnya," 2016. [Online]. Available: https://ilmuprogram.com/2016/12/17/arduino-penjelasan-andmacam-macamnya/.

[11] Muhammad Ichwan, M. G. Husada, and M. I. A. Rasyid, "Jurnal Informatika," Pembang. PROTOTIPE Sist. Pengendali. Peralat. List. PADA Platf. ANDROID, vol. 4, no. 1, pp. 13-25, 2013.

[12] Mamik Shofiatul Nikmah, "Tachometer Non Contact Berbasis Arduino," 2016.

[13] "5MW Diffuse Laser Sensor," 5MW Diffuse Laser Sensor, 2016. [Online]. Available: http://lapantech.com/5MW-Diffuse-Laser-Sensorline-follower-robotika.

[14] A. Zainuri, U. Wibawa, and E. Maulana, Jurnal EECCIS, vol. 9, no. 2. Malang, 2015.

[15] T. U. Kalsum and Hermawansyah, "Jurnal Media Infotama," SIMULASI BUKA TUTUP PINTU DENGAN MENGGUNAKAN Bhs. PEMPROGAMAN Borl. DELPHI 07, vol. 7, no. 2, p. 27, 2011. 